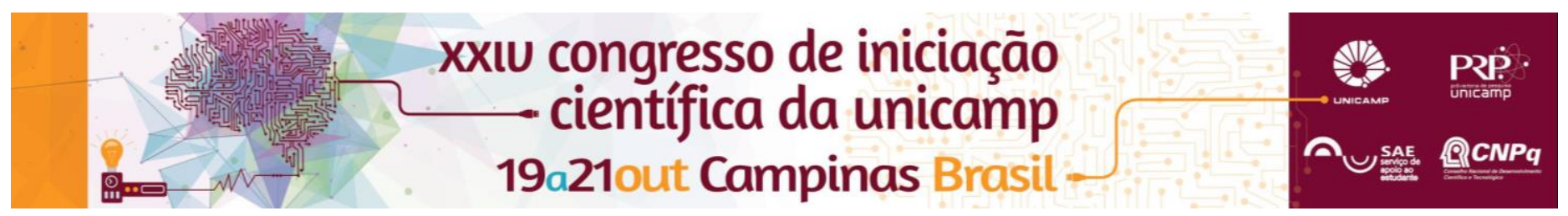

\title{
Problemas oclusais em indivíduos de 6 a 9 anos de idade, matriculados em escolas municipais.
}

\author{
Paulo S.S.R. Calori, Marcelo C. Meneguim, Emilio Prado, Silvia A. Vedovello.
}

\begin{abstract}
Resumo
Este estudo tem como objetivo avaliar a associação entre os problemas oclusais e classe social em indivíduos de 6 a 9 anos de idade matriculados em escolas municipais. A amostra foi calculada baseada na experiência de cárie e problemas oclusais de estudos anteriores com margem de erro de $10 \%$, perda amostral de $20 \%$ e nível de confiabilidade de $95 \%$. Foram avaliadas características clínicas odontológicas tais como: cárie dentária e problemas oclusais. Os critérios utilizados para a avaliação clínica da cárie são os preconizados pela OMS (1999). Para a avaliação das características oclusais foram utilizados os índices de Foster e Grabowskyem. De 468 crianças, 232 não apresentam má oclusão.Concluí-se que 50,42\% das crianças apresentam má oclusão.
\end{abstract}

\section{Palavras-chave:}

Qualidade de vida, epidemiologia, saúde bucal.

\section{Introdução}

Os problemas oclusais podem ser definidos como alterações do crescimento e desenvolvimento orofacial que afetam principalmente os dentes, músculos e ossos maxilares na dentição decídua e permanente. De acordo com estudos epidemiológicos, a maior prevalência e gravidade encontram-se na dentição permanente (MichelCrosato et al., 2005; Fernandes et al., 2007;Azenha et al.,2010;Boecket al.,2013).

O fato de possuir a má oclusão também influencia na qualidade de vida do indivíduo, interferindo na interação social e no bem-estar psicológico, portanto, as dimensões do impacto dental e função social são tão importantes quanto às medidas clínicas normativas, se não mais (Oliveira, Sheiham, 2004; Marques et al., 2005; Moura et al., 2012;).

A distribuição das alterações oclusais segue o padrão de iniquidade social de outros agravos à saúde. Estas informações são úteis para a formulação de critérios relacionados tanto com a distribuição e previsão de recursos quanto a prioridade no tratamento ortodôntico fundamentados no princípio de equidade da atenção na saúde bucal (Peres et al.; 2013).

Neste contexto, o presente projeto de pesquisa tem por objetivo analisar a associação entre problemas oclusais, índice de cárie (CPO-d) e a classe social em escolares da rede municipal de ensino.

\section{Resultados e Discussão}

Foram realizadas visitas na escolas publicas da cidade de Piracicaba, foram feitos levantamentos de índices de má oclusão e cárie dentaria, nessa pesquisa levamos em conta somente os índices de má oclusão.

A avaliação oclusal será realizada por meio de inspeção clínica visual em ambiente de luz natural, utilizando-se equipamentos de proteção individual (jaleco, gorro, máscara, luvas descartáveis e óculos), abaixador de língua (espátula de madeira), sonda tipo IPC e afastador labial individual. Os dados foram tabulados em planilha com Excel para analise estatística.

Segundo o índice de Foster, com crianças com idade entre 6 a 9 anos, em uma amostra de 468 crianças, 232 não apresentam má oclusão, e as outras 236 apresentam.

DOI: 10.19146/pibic-2016-50971
Segundo Grabowsky, com crianças com idade entre 6 a 9 anos, em uma amostra de 468 crianças, 183 não apresentam má oclusão, e as outras 285 apresentam.

\section{Conclusões}

Concluímos que usando o índice de Foster 50,42\% das crianças apresentam má oclusão, e segundo o índice de Grabowsky 60,98\% das crianças apresentam má oclusão. Com ambos índices a diferença de gênero foi mínima.

\section{Agradecimentos}

PQ Silvia A. Vedovello, da FHO- UNIARARAS- pelo empenho, conhecimento e atenção ao trabalho realizado. PG Emilio Prado pela atenção e dedicação.

CNPq e a PRP-Unicamp pela concessão da bolsa..

\footnotetext{
${ }^{1}$ Feu D, Quintão CCA, Miguel JAM. Indicadores de qualidade de vida e sua importância na Ortodontia. Dental Press J Orthod 2010; Nov-Dec; 15(6):61-70.

2 Organização Mundial da Saúde. Levantamentos básicos em saúde bucal. Tradução de Ana Júlia Perrotti Garcia. 4.ed. São Paulo: Santos, 1999. 66p.
} 